\title{
Corrigendum to "A Novel Curcumin-Galactomannoside Complex Delivery System Improves Hepatic Function Markers in Chronic Alcoholics: A Double-Blinded, randomized, Placebo-Controlled Study"
}

\author{
Naveen T. Krishnareddy ${ }^{D},{ }^{1}$ Justin V. Thomas, ${ }^{2}$ Saritha S. Nair, ${ }^{3}$ Johannah N. Mulakal, ${ }^{3}$ \\ Balu P. Maliakel, ${ }^{3}$ and I. M. Krishnakumar ${ }^{3}{ }^{3}$ \\ ${ }^{1}$ Life Care Hospital, Bangalore, India \\ ${ }^{2}$ Leads Clinical Research \& Bio Services Pvt. Ltd., Bangalore, India \\ ${ }^{3}$ R $D$ Centre, Akay Flavours \& Aromatics Ltd., Kerala, India
}

Correspondence should be addressed to Naveen T. Krishnareddy; ntklifecare@gmail.com

Received 9 January 2019; Accepted 28 January 2019; Published 3 March 2019

Copyright (C) 2019 Naveen T. Krishnareddy et al. This is an open access article distributed under the Creative Commons Attribution License, which permits unrestricted use, distribution, and reproduction in any medium, provided the original work is properly cited.

In the article titled "A Novel Curcumin-Galactomannoside Complex Delivery System Improves Hepatic Function Markers in Chronic Alcoholics: A Double-Blinded, randomized, Placebo-Controlled Study" [1], the dosage of drugs in the Materials and Methods and Results was given incorrectly as (250 $\mathrm{mg} \times 1$ )/ day. It should be corrected to (250 $\mathrm{mg} \times 2$ )/ day.

\section{References}

[1] N. T. Krishnareddy, J. V. Thomas, S. S. Nair, J. N. Mulakal, B. P. Maliakel, and I. M. Krishnakumar, "A novel curcumingalactomannoside complex delivery system improves hepatic function markers in chronic alcoholics: A double-blinded, randomized, placebo-controlled study," BioMed Research International, vol. 2018, Article ID 9159281, 10 pages, 2018. 

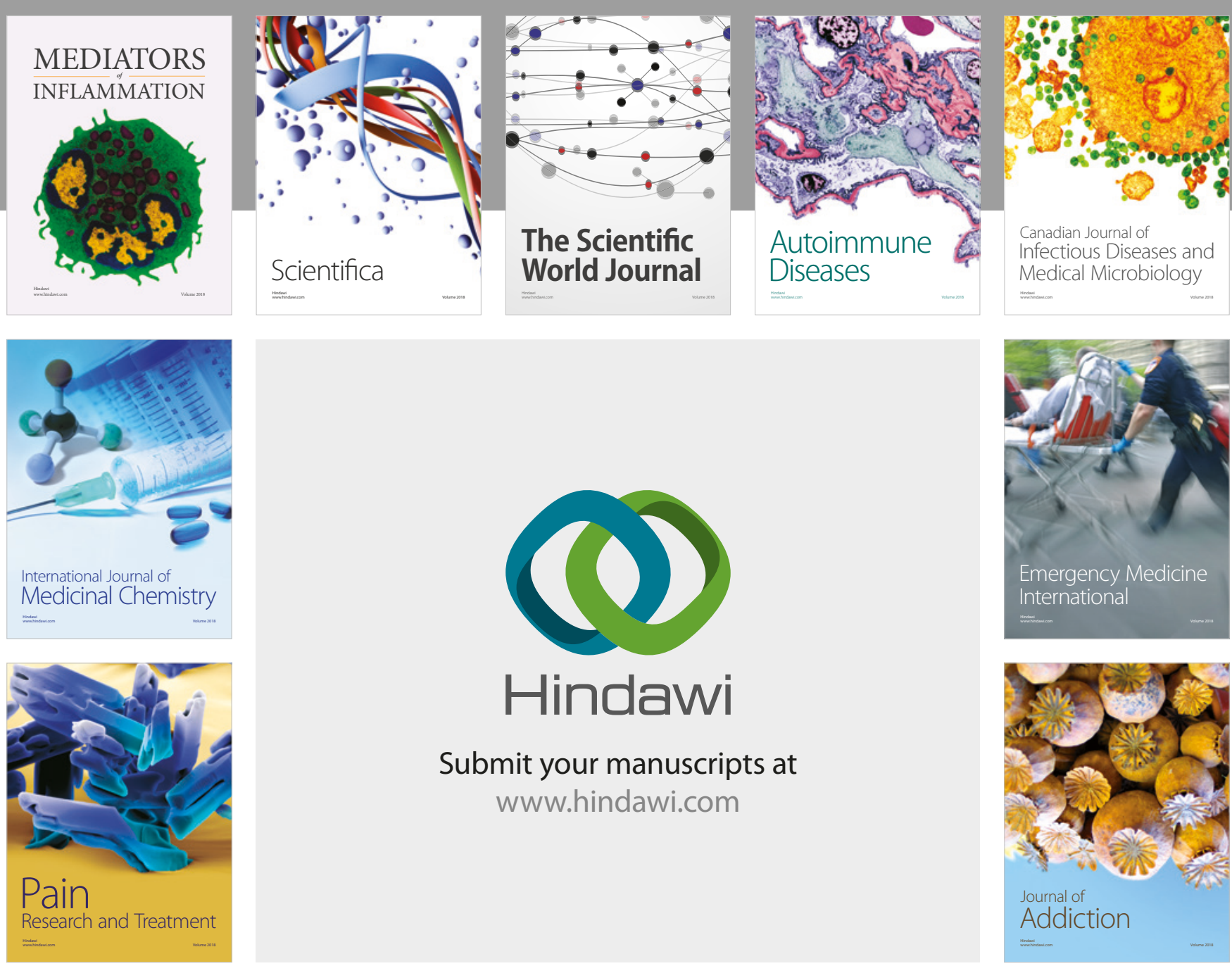

Canadian Journal of
Infectious Diseases and Medical Microbiology

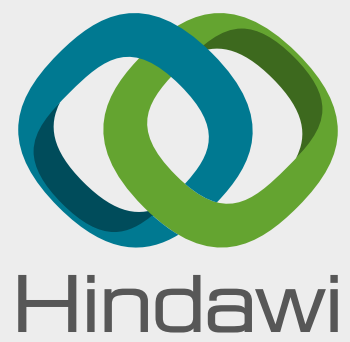

Submit your manuscripts at

www.hindawi.com
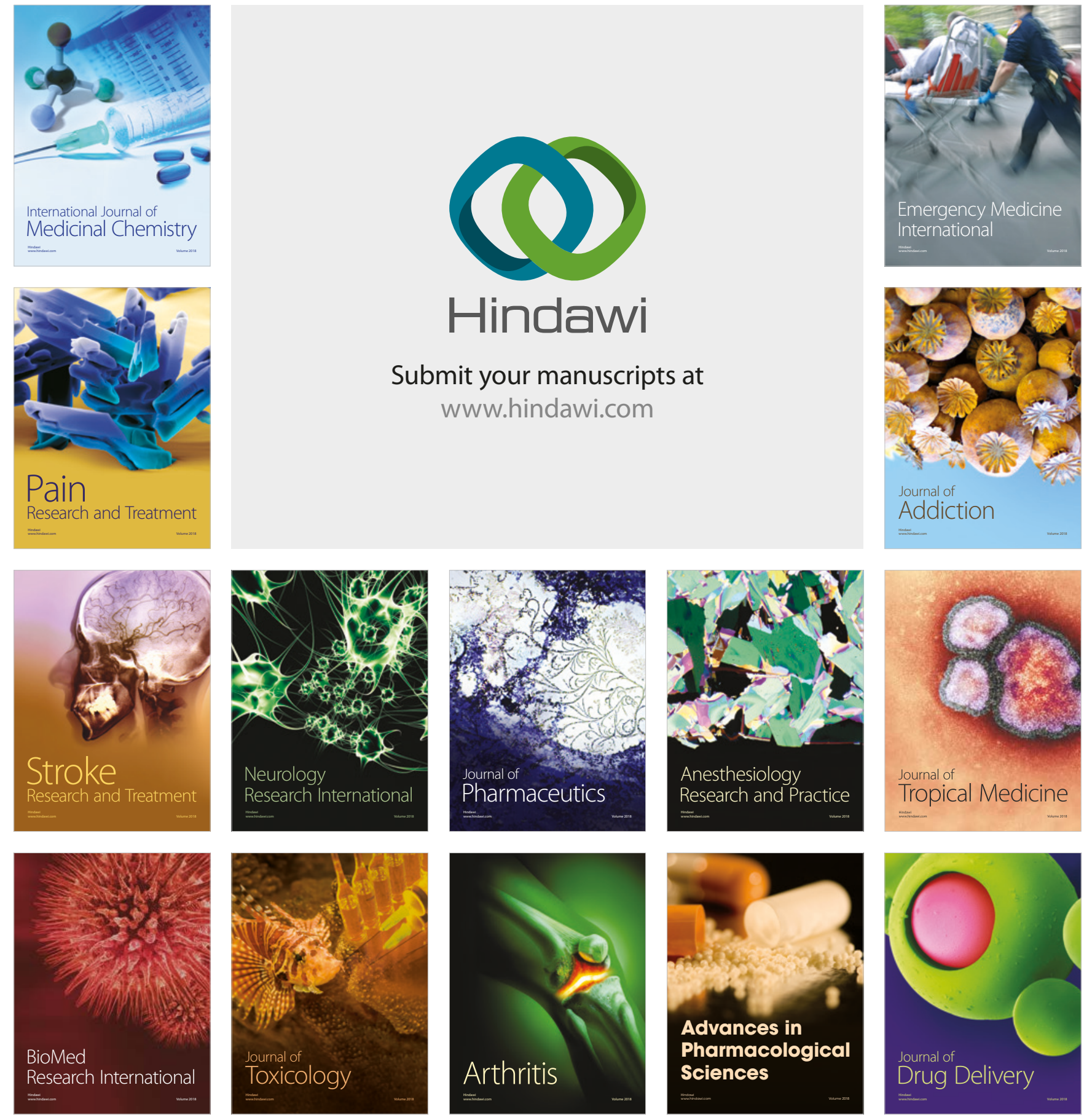